\title{
Predicting Behavior Problems in Korean Preschoolers: Interactions of the SLC6A4 Gene and Maternal Negative Affectivity
}

\author{
Junghee $\mathrm{Ha}^{1}$, Hey Jung Jun ${ }^{2}$, Hyewon Shin ${ }^{3}$, Ick Joong Chung ${ }^{4}$, Eunmie Park ${ }^{5}$, Sung Kil Min ${ }^{6}$, Eunjoo Kim \\ ${ }^{1}$ Department of Psychiatry and Institute of Behavioral Science in Medicine, Yonsei University College of Medicine, ${ }^{2}$ Department of Child and \\ Family Studies, College of Human Ecology, Yonsei University, ${ }^{3}$ Department of Child Studies, Seokyeong University, ${ }^{4}$ Department of Social \\ Welfare, Ewha Womans University, ${ }^{5}$ Department of Social Welfare, Seoul Jangsin University, Seoul, ${ }^{6}$ Department of Neuropsychiatry, Hyoja \\ Geriatric Hospital, Yongin, Korea
}

\begin{abstract}
Objective: This study aimed to investigate whether maternal negative affectivity (MNA) moderates the effect of genetic polymorphism of SLC6A4 on behavior problems in children.

Methods: Study participants comprised 143 preschoolers and their mothers from South Korea. The Childhood Behavior Checklist and Emotionality, Activity, and Sociability adult scale were used to measure child behavior and maternal affectivity. DNA from saliva was genotyped to determine serotonin transporter polymorphism.

Results: MNA appeared to exert effects in externalizing $(b=5.78, p<0.001)$ and internalizing problems $(b=6.09, p<$ 0.001). Interaction between SLCA4 polymorphism and MNA showed effects on externalizing $(b=-7.62, p<0.01)$ and internalizing problems $(b=-9.77, p<0.01)$. Children with two short alleles showed considerable differences in both externalizing and internalizing problems according to MNA; however, children with one short allele or none showed relatively few differences in behavior problems due to maternal affectivity.

Conclusion: The effect of SLC6A4 polymorphism on child behavior seemed to be moderated by MNA. In addition, the impact of MNA was found to vary based on a child's genetic risk. High MNA may trigger the risk allele while low MNA causes the risk allele to illicit less behavior problems. Children with two short variants of the SLC6A4 gene may benefit from intervention that modulates MNA.
\end{abstract}

KEY WORDS: Gene-environment interaction; SLC6A4 protein; Maternal behavior; Child behavior.

\section{INTRODUCTION}

Behavior problems in preschoolers are a risk to the child's development. ${ }^{1,2)}$ Behavior problems can be grouped into internalizing and externalizing problem behaviors. ${ }^{3)}$ Internalizing behaviors are internally directed and include over-controlled, withdrawn, depressed, anxious, and avoidant behaviors. ${ }^{4,5}$ Externalizing behaviors are directed toward the external environment and include uncontrolled rebellious, destructive, and oppositional beha-

Received: January 3, 2018 / Revised: March 22, 2018

Accepted: March 28, 2018

Address for correspondence: Eunjoo Kim, MD, PhD

Department of Psychiatry, Gangnam Severance Hospital, Yonsei

University College of Medicine, 211 Eonju-ro, Gangnam-gu,

Seoul 06273, Korea

Tel: +82-2-2019-3345, Fax: +82-2-3462-4304

E-mail: ejkim96@yuhs.ac

ORCID: https://orcid.org/0000-0003-3061-2051 viors. ${ }^{6,7)}$ Externalizing behavior problems have been reported to become less frequent as children get older. However, considerable evidence indicates that externalizing behavior problems may extend into adulthood, increasing the risk for other psychopathology, including substance use and disruptive behavior disorders. ${ }^{8-11)}$ Internalizing problems in early childhood put children at risk for developing mood/anxiety and substance use disorders. Taken together, these behavior problems are seen at a high rate in preschoolers, and have been shown to be associated with social maladjustment, poor academic achievements, and poor relationships in later school-age period. ${ }^{12,13)}$ Therefore, identifying factors that affect internalizing and externalizing behavior problems in preschool children is important.

Genetic factors may contribute to behavior, expression of traits, and interact with environmental factors affecting

(ㄷ) This is an Open-Access article distributed under the terms of the Creative Commons Attribution Non-Commercial License (http://creativecommons.org/licenses/by-nc/4.0) which permits unrestricted non-commercial use, distribution, and reproduction in any medium, provided the original work is properly cited. 
child development and behavior. ${ }^{14)}$ In particular, the serotonergic system is involved in both internalizing and externalizing problems. ${ }^{15,16)}$ The serotonin $(5-\mathrm{HT})$ transporter gene (SERT, also known as SLC6A4) regulates serotonergic neurotransmission. Polymorphism (5-HTTLPR) in the promoter region of the $S \angle C 6 A 4$ results in two variants: a short $(s)$ and long $(l)$ allele. The variants differ in 44 nucleotides and effect transporter expression and function. ${ }^{17-19)}$ The $s$ variant is associated with reduced transcription of SLC6A4 and serotonin reuptake, while the $l$ variant provides increased transcription and function of the serotonin transporter, resulting in less synaptic serotonin. ${ }^{18,20,21)}$ Prior studies have suggested that a genetic difference in SLC6A4 may be involved in an individual's susceptibility to internalizing and externalizing problems. Caspi et al. ${ }^{22)}$ first suggested that genetic differences in susceptibility to environmental impacts might be associated with internalizing problems, including depression. When children experience trauma in early life, carriers of the $s$ allele were more likely to suffer from depression than carriers of the $l$ allele. Moreover, after a stressful event in early life, individuals with two copies of the $s$ allele (genotype $s / s$ ) showed decreased $S \angle C 6 A 4$ gene transcription and increased vulnerability to depression and other mood disorders. ${ }^{23)}$ The $s$ variant of the SLC6A4 gene has also been shown to be associated with externalizing problems, such as aggressive behavior and alcohol dependence. ${ }^{24}$

Both internalizing and externalizing problems in preschool-aged children are related to poor emotional regulation. ${ }^{25-27)}$ That is, the early cumulative risk of behavioral problems is mediated by children's self-regulation. ${ }^{28)}$ Emotional self-regulation develops rapidly in the early stages of life and gradually improves as children mature. $^{29)}$ By the end of the preschool period children have developed new and increasingly complex ways of regulating their emotions, undergoing dramatic change within the first five years of their life. ${ }^{30)}$ During preschool, emotion regulation becomes necessary to deal with their increasingly complex emotions and demands of a social world. Failure to achieve emotional regulation during the preschool period can impede social interaction, leading to outbursts of temper and distress, and this is associated with social competence. ${ }^{31)}$ This age-period is the time when behavior problems are highly influenced by parental characteristics, and therefore, is a good period in which to implement preventive interventions to keep problem behaviors from developing in later middle-childhood and adolescence. Children with externalizing problems have low attention and inhibitory control, which is related to poor emotional regulation. ${ }^{27,32)}$ Children display more externalizing behaviors if their emotional regulation ability is low. ${ }^{26)}$ Although children with internalizing problems may appear to be over controlled, in that their behavior is inhibited, this type of excess emotional regulation is passive, not volitional. ${ }^{25,33)}$

One important environmental factor that affects a child ability to regulate emotion and behavior is the parent's negative affectivity. ${ }^{34,35)}$ Negative affectivity is a higher mood dimension that reflects the experience of negative emotions and poor self-control. ${ }^{36)}$ It is associated with the development of the child's internalizing and externalizing problems by diminishing the ability of the child to develop emotional regulation. In contrast, parental positive affectivity promotes self-regulation by inducing a child positive emotions and enhancing their attempts to regulate emotion. ${ }^{37,38)}$ Despite increasing evidence for the interplay between a child's behavior problem and their parents' negative affectivity, previous studies have focused more on behavior and genetic factors than on environmental factors, such as maternal affectivity. However, the interaction effect of environment and genetics on a child's behavior has been investigated in recent studies. For example, Sulik et al. ${ }^{39)}$ reported that the interaction between the child's serotonin transporter gene and mother's parenting style would predict the development of behavior problems. Other studies suggested that individuals with the short allele $(s)$ are generally sensitive to psychosocial interventions, whereas individuals with the long variant $(l)$ are insensitive, to the same type of interventions. ${ }^{22,40)}$

Therefore, based on the findings from previous studies, we investigated whether maternal negative affectivity (MNA) moderates the effect of genetic polymorphism of the serotonin transporter gene on behavior problems in children in the present study. We hypothesized that by affecting SLC6A4 polymorphism, MNA would be indirectly or directly associated with externalizing and internalizing problems. The effects of MNA on a child internalizing and externalizing behavior would vary depending on the genetic risk, such that children at high genetic risk $(s / s$ genotype) would benefit differentially from intervention, compared to children at low genetic risk ( $s / l$ or $l / l$ genotype). 


\section{METHODS}

\section{Sample and Procedure}

A sample of 143 preschool students ( 75 boys and 68 girls) and their mothers were recruited from seven daycare centers in the Seoul and Gyeonggi areas of South Korea. Inclusion criteria were (1) preschoolers aged 4 to 6 years; and (2) no history of psychiatric diagnosis, such as attention deficit hypersensitivity disorder, depressive disorder, anxiety disorder, oppositional defiant disorder, or tic disorder. Exclusion criteria were (1) an intelligence quotient score below 70 and (2) past or current neurologic disorder. A researcher visited each daycare center and suggested participation in the study with an explanation to the mothers of preschoolers. To exclude children with psychopathologies, we asked the caregivers of participating children whether their children had ever been diagnosed with any current or past psychiatric disorders or whether any significant developmental or behavioral problems had been reported by teachers at their preschool. Children reported as having serious problems were excluded from participating in our study. Intelligence was measured using the standardized Korean Wechsler Preschool and Primary Scale of Intelligence (K-WPPSI) for children. ${ }^{41)}$ The mean age of the students was 5.33 (standard deviation $[S D], 0.948)$. Table 1 shows the demographic information. All participants were Korean. The $60 \%$ of the children reported their mothers as their primary caregivers. Mothers of the participating children completed the Child Behavior Checklist (CBCL) for their children and the Emotionality, Activity, and Sociability (EAS) adult scale for themselves. Of the 143 caregivers, 15

Table 1. Sample statistics

\begin{tabular}{lcc}
\hline \multicolumn{1}{c}{ Characteristic } & Data & Missing data \\
\hline Age* $^{*}$ & $48(33.6)$ & \\
$4 \mathrm{yr}$ & $95(66.4)$ & \\
$6 \mathrm{yr}$ & & \\
Gender & $75(52.4)$ & \\
Male & $68(47.6)$ & \\
Female & & \\
SLC6A4 polymorphism & $89(62.2)$ & \\
SS & $44(30.8)$ & \\
SL & $9(6.3)$ & 46 \\
LL $_{\text {Intelligence quotient }}^{\dagger}$ & $97(67.8)$ & \\
\hline
\end{tabular}

Values are presented as number (\%).

Mean \pm standard deviation: $* 5.33 \pm 0.948$ and ${ }^{\dagger} 100.29 \pm 14.88$. did not submit the questionnaire, and thus, only CBCL data for the remaining 128 were analyzed. The mean T-scores in the attention problem subscale for CBCL was 52.74 (range, 50-70), suggesting that attention levels for our participating children were mostly within the normal range. An independent $t$ test was conducted to exclude the possibility that the excluded group $(n=15)$ were more affected by specific behavior problems or maternal depression or MNA than the children who submitted the questionnaires. For this purpose, we compared the mean of the Limit Setting scale from the Parent-Child Relationship index (PCRI) as an index reflecting the child's behavior problems $(44,45)$ and the scores of the EAS and Center for Epidemiological Studies-Depression (CED-S) questionnaires to assess the mother's emotional status and depression. There was no significant difference between the two groups (PCRI score: $\mathrm{t}(121)=0.468, p=0.641,95 \%$ confidence interval $[\mathrm{Cl}]=-3.67$ to 0.593 ; EAS score: $\mathrm{t}(129)=$ $1.224, p=0.223,95 \% \mathrm{Cl}=-1.58$ to 0.674 ; CED-S score: $\mathrm{t}$ (0.132) $=0.480, p=0.091,95 \% \mathrm{Cl}=0.045$ to 0.590$)$. The institutional review boards of each participating site approved the study. Written informed consent was obtained from all parents of the participating preschoolers.

\section{DNA Extraction and 5-HTTLPR Genotyping}

Saliva samples for DNA isolation were collected from 143 preschool students using the Oragene DNA Self Collection Kit (DNA Genotek, Ottawa, ON, Canada). Kits were stored at room temperature and shipped for molecular genetic analysis. DNA was extracted from saliva according the manufacturer's protocol (Oragene ${ }^{T M}$ DNA Purification Protocol; DNA Genotek). Genotyping for the serotonin-transporter-linked-polymorphic region (5-HTTLPR) was performed using the genetic analysis service at DNA Link, Inc. (Seoul, Korea). The primer sequence for the 5-HTTLPR polymorphism was synthesized using a previously described protocol, ${ }^{42)}$ with the forward primer having the sequence 5'-ATGCCAGCACCTAACCCCTAATGT-3' and the reverse 5'-GGACCGCAAGGTGGGCGGGA-3': this amplifies a 419base pair product for the 16 repeat (' $l$ ') allele and a 375-base pair product for the 14 repeat (' $s$ ) allele. Polymerase chain reaction (PCR) was carried out using the following steps: initial 15-minute denaturing step at $95^{\circ} \mathrm{C} ; 35$ cycles at $94^{\circ} \mathrm{C}$ for 30 seconds; $66^{\circ} \mathrm{C}$ for 30 seconds; $72^{\circ} \mathrm{C}$ for 40 seconds; and a final extension phase 
of $72^{\circ} \mathrm{C}$ for 15 minutes. The PCR products were examined by electrophoresis for 30 minutes on a $2.5 \%$ agarose gel stained with ethidium bromide (0.03\%). DNA sequencing of the PCR products for several subjects was performed to confirm polymorphism of the serotonin transporter gene, SLC6A4.

\section{Measures}

\section{Child internalizing and externalizing behavior problems}

The CBCL is an assessment tool completed by parents to measure the externalizing and internalizing symptoms of their children. The Korean version of $\mathrm{CBCL}(\mathrm{K}-\mathrm{CBCL})$ is a standardized and validated instrument, which provides ratings of behavior for children aged 4 to 17 years. ${ }^{43)}$ The K-CBCL is comprised of 117 items and three subscales, including total problem score, and externalizing and internalizing scores. The instrument has eight symptom categories, including emotionally reactive, anxious/depressed, withdrawn, somatic complaints, sleep problems, attention, aggression, and other problems. Data are reported as both raw scores and sex and age normalized $\mathrm{T}$ scores. The $\mathrm{T}$ scores are standardized scores derived from raw scores to facilitate comparisons between groups. Higher T scores indicate a greater degree of behavioral and emotional problems.

\section{Maternal negative affectivity}

To measure MNA, we used the EAS adult scale developed by Buss and Plomin. ${ }^{44)}$ The EAS adult scale has been used in research and clinical practice in Korea because of its simplicity of use, validity of content and reliability. It is composed of three factors: emotionality, activity, and sociability. In this study, we measured emotionality, including emotional instability, emotional anxiety and emotional expression (Supplement 1). Emotionality was assessed with 12 items, measured on 5-point Likert scale, ranging from "not at all" (1 point) to "very much" (5 points). The higher the score, the more negative the emotions. The Cronbach's $\alpha$ value of the 12 items was 0.83 .

\section{Data Analyses}

To test the strength of association among variables, simple bivariate correlations were computed. We used PROCESS ${ }^{45)}$ to test two simple mediation models that con- sisted of bootstrapping with 143 samples. PROCESS is a bootstrapping that creates a representation of the sampling distribution of the indirect effects by randomly resampling the original sample. Therefore, it can generate a new distribution that acts as an empirical approximation of the indirect effect in the original population. ${ }^{46)}$ Multiple regressions were performed using PROCESS to investigate the potential interaction between SLC6A4 polymorphisms and maternal factors on child behavior problems with either internalizing T-score or externalizing T-score as the dependent variables. The goal was to determine whether MNA moderates the relationship between SLC6A4 genotype and behavior problems. Additionally, we calculated conditional effects of MNA on internalizing and externalizing behavior problems. This estimates how much two cases that differ by one unit on MNA differ regarding behavior problems, when Mequals some specific value. The value of $M$ is set to represent a SD below the mean ("low"), the mean ("moderate"), and a SD above the mean ("high"). All analyses were performed using IBM SPSS ver. 23.0 for Windows (IBM Corp., Armonk, NY, USA) and $p$ values of $<0.05,0.01$, and 0.001 were used for significance.

\section{RESULTS}

\section{Sample Statistics}

Table 2 shows the means and SD of demographic, clinical and genetic information of the participants. In this study, the frequency of genotypes for SLC6A4 polymorphism was $89(62 \%)$ for $s / s, 44(31 \%)$ for $s / l, 9(6 \%)$ for $l / l$. Ninety-three percent of the 143 participants had an $s$ allele (genotyped $s / s$ or $s / l$ ). This genotype distribution is similar to that previously reported in the Korean population. ${ }^{47)}$ Ninety-three percent of the 143 participants had an $s$ allele (genotyped $s / s$ or $s / l$ ). This is consistent with the results from a previous study in the Korean population: SLC6A4 polymorphisms exhibit ethnic variation, and the frequency of $s$ allele is high in the Korean population. ${ }^{47-51)}$ Therefore, we grouped individuals with $s / l$ and $l / l$ alleles into one category, and compared them with $s / s$ individuals. Genotypes categorized in this manner were not significantly different by sex.

\section{Correlation Analysis}

Table 2 presents the correlation among four variables 
Table 2. Bivariate correlations between variables

\begin{tabular}{lccc}
\hline \multicolumn{1}{c}{ Variable } & Maternal negative affectivity & IP & SLC6A4 \\
IP & $0.323^{* * *}$ & 1 & 1 \\
EP & $0.331^{* * *}$ & $0.728^{* * *}$ & -0.092 \\
SLC6A4 polymorphism & 0.055 & -0.090 & $46.641 \pm 9.996$ \\
Mean \pm SD & $2.714 \pm 0.57$ & $46.383 \pm 8.556$ & 46.5 \\
\hline
\end{tabular}

$\mathrm{IP}$, internalizing problems; EP, externalizing problems; SD, standard deviation.

$* * * p<0.001$.

Table 3. Regression analysis of predicting child internalizing problems

\begin{tabular}{|c|c|c|c|c|}
\hline Variable & Estimate $(b)$ & SE & $t$ & $95 \% \mathrm{Cl}$ \\
\hline Maternal negative affectivity & 4.85 & 1.22 & $3.97^{* * *}$ & 2.43 to 7.28 \\
\hline SLC6A4 polymorphism & -0.97 & 1.47 & -0.66 & -3.89 to 1.95 \\
\hline Maternal negative affectivity $\times \mathrm{SLCA} 4$ polymorphism & -8.06 & 2.51 & $-3.21^{* *}$ & -13.04 to -3.09 \\
\hline
\end{tabular}

$\mathrm{SE}$, standard error; $95 \% \mathrm{Cl}, 95 \%$ confidence interval.

** $p<0.01$, *** $p<0.001$.

Table 4. Conditioning effect(s) of maternal negative affectivity on Internalizing problems through SLC6A4 polymorphism

\begin{tabular}{|c|c|c|c|c|c|}
\hline Effect & $b$ & SE & $t$ & $p$ & $95 \% \mathrm{Cl}$ \\
\hline Low: -0.583 & 3.79 & 2.06 & 1.81 & 0.07 & -0.35 to 7.81 \\
\hline Moderate : 0 & -0.97 & 1.47 & -0.66 & 0.51 & -3.89 to 1.95 \\
\hline High: 0.583 & -5.67 & 2.09 & -2.71 & 0.01 & -9.82 to -1.52 \\
\hline
\end{tabular}

SE, standard error; $95 \% \mathrm{Cl}, 95 \%$ confidence interval.

used in this study. Both internalizing and externalizing problems had a positive correlation with MNA score ( $r=0.32, p<0.001, r=0.33, p<0.001)$. SLC6A4 genotype was not correlated with MNA score $(r=0.055)$, child internalizing problems $(r=-0.09)$, or externalizing problems $(r=-0.09)$. This suggests that higher MNA is associated with greater risk for internalizing and externalizing problems in preschoolers.

\section{Moderation Analysis}

The results from multiple regression analysis supported our hypothesized model that MNA score moderates the association between SLC6A4 polymorphisms and child internalizing (Tables 3, 4)/externalizing (Tables 5, 6) problems. MNA score showed main effects in predicting internalizing $(b=4.85, p<0.001)$ and externalizing $(b=5.78, p<0.001)$ behavior problems. The interaction of the SLC6A4 polymorphisms and MNA score predicted internalizing behavior problems $\left(R^{2}=0.18, F=8.53, p<\right.$ $0.001)(b=-8.06, p<0.001,95 \% \mathrm{Cl}=-3.04$ to -3.09$)$ (Table 3). The interaction of the SLC6A4 polymorphisms and MNA score predicted externalizing behavior prob- lems $\left(R^{2}=0.16, F=7.47, p<0.001\right)(b=-7.62, p<0.01$, $95 \% \mathrm{Cl}=-13.53$ to -1.72 ) (Table 5). However, the main effect of SLC6A4 polymorphism in internalizing $(p=0.51$, $95 \% \mathrm{Cl}=-3.89$ to 1.95$)$ and externalizing $(p=0.41,95 \%$ $\mathrm{Cl}=-4.90$ to 2.03 ) problems were not statistically significant. These results indicated that MNA moderates the relationship between $S L C 6 A 4$ polymorphisms and child internalizing/externalizing problems. Interestingly, children with genotype $s / s$ had significant internalizing/externalizing behavior problems related to the level of MNA (Fig. 1). We used a third quartile to examine the interactions and to estimate the conditional effects of the predictor (internalization problem) at low, moderate, and high levels of the moderator (MNA). When the moderator was high (mean, $0.583 ; 95 \% \mathrm{Cl},-9.82$ to -1.52 ) and significant ( $p=0.01$ ) (Table 4). For externalizing problems, we probed significant interactions using the third quartile to estimate the conditional effects of the predictor (external problems) at low, moderate, and high levels of the moderator (MNA). When the moderator was high (mean, $0.583 ; 95 \% \mathrm{Cl},-10.80$ to -0.96$)$, and significant $(p=0.02)$ (Table 6). 
Table 5. Regression analysis of predicting child externalizing problems

\begin{tabular}{lcccc}
\hline \multicolumn{1}{c}{ Variable } & Estimate $(b)$ & SE & $t$ & $95 \% \mathrm{Cl}$ \\
\hline Maternal negative affectivity & 5.78 & 1.45 & $3.98^{* * *}$ & 2.91 to 8.66 \\
SLC6A4 polymorphism & -1.44 & 1.75 & -0.82 & -4.90 to 2.03 \\
Maternal negative affectivity $\times$ SLC6A4 polymorphism & -7.62 & 2.98 & $-2.56^{* *}$ & -13.53 to -1.72 \\
\hline
\end{tabular}

$\mathrm{SE}$, standard error; $95 \% \mathrm{Cl}$, 95\% confidence interval.

${ }^{* *} p<0.01,{ }^{* * *} p<0.001$.

Table 6. Conditioning effect(s) of maternal negative affectivity on externalizing problems through SLC6A4 polymorphism

\begin{tabular}{lrrrrc}
\hline \multicolumn{1}{c}{ Effect } & $b$ & SE & $t$ & $p$ & $95 \% \mathrm{Cl}$ \\
\hline Low: -0.583 & 3.01 & 2.45 & 1.23 & 0.22 & -1.84 to 7.85 \\
Moderate $: 0.0000$ & -1.44 & 1.75 & -0.82 & 0.41 & -4.90 to 2.03 \\
High: 0.583 & -5.88 & 2.49 & -2.36 & 0.02 & -10.80 to -0.96 \\
\hline
\end{tabular}

SE, standard error; $95 \% \mathrm{Cl}$, $95 \%$ confidence interval.
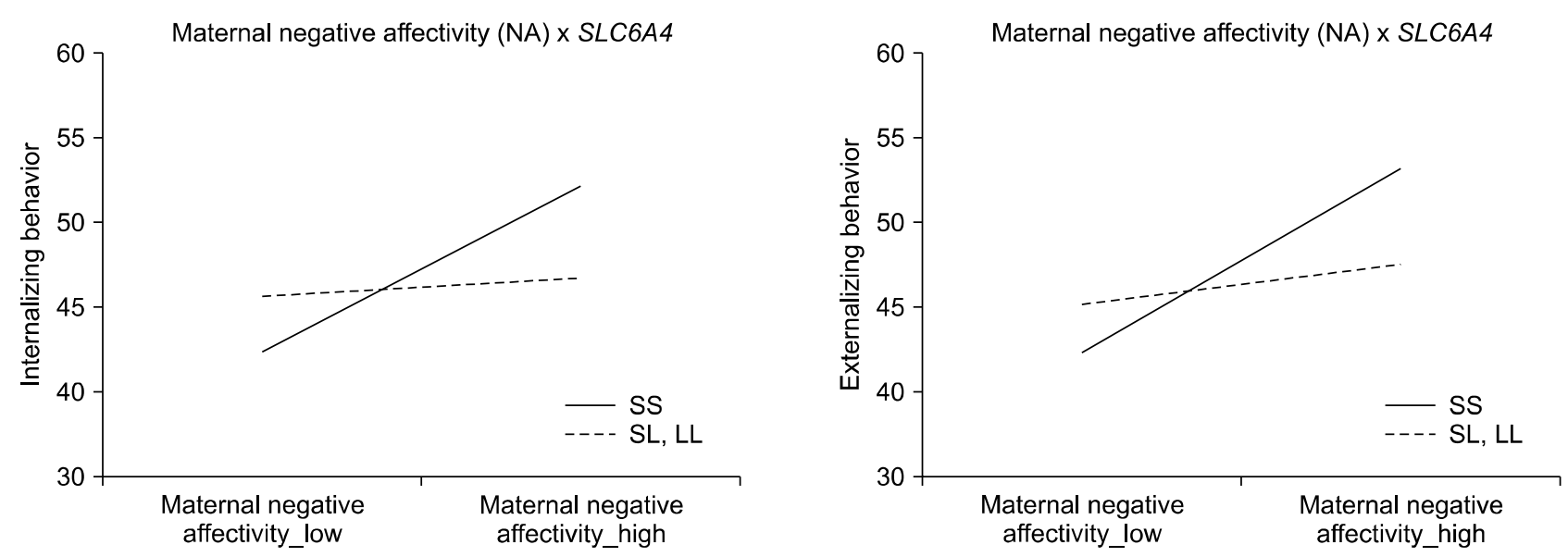

Fig. 1. Moderator effects of maternal negative affectivity on the relationship between $S L C 6 A 4$ polymorphisms and child internalizing/externalizing behaviors.

\section{DISCUSSION}

We investigated the interplay of MNA on the association between genetic polymorphism and behavior problems in children. Few studies have examined how genes and maternal affectivity interact and affect the behavior problems of children. ${ }^{49,52,53)}$ The present study is one of the first to show that MNA mediates the effects of serotonin transporter gene polymorphisms on Korean preschooler's behavior problems.

Children gradually learn how to regulate their emotion to meet social demands. ${ }^{30)}$ Problems in regulating emotion in early life are associated with both internalizing and externalizing behavior problem in school age. ${ }^{54,55)}$ External support and good modeling from caregivers are important in the development of emotional regulation. ${ }^{30)}$ Maternal negative affectivity, by failing to model self-regulation, could negatively affect a child's behavior problems. ${ }^{56)}$ Parenting with positive emotions, by encouraging positive emotions of children and by strengthening active attempts to control emotions, is related to emotional regulation of the child. ${ }^{37,38)}$ Parenting with negative emotions, including unsupportive and punitive responses to the behavior of the child is also associated with negative emotional consequences and increased risk of internalizing and externalizing problems. ${ }^{34,57,58)}$

Serotonin is involved in controlling depression, anxiety, and aggressive behavior, ${ }^{8,22,39,59)}$ and these psychopathologies are related to internalizing and externalizing problems in children. ${ }^{5,11)}$ A short variant of 5 HTTLPR is as- 
sociated with increasing susceptibility to mood disorders and substance abuse, especially in the context of stressful life events. ${ }^{22,24)}$ Meta-analysis revealed that individuals with the $s / s$ genotype experience a marked increase in cortisol response to acute stress, ${ }^{60,61)}$ and heightened amygdala activity when faced with fearful stimuli. ${ }^{62)}$ Enhanced physiological responses and fear conditioning among carriers of one or two copies of the $s$ allele could increase the risk of developing internalizing and externalizing behaviors. ${ }^{54,63-65)}$ In addition, frequent use of active coping strategies, including distraction or support seeking, are related to fewer internalizing and externalizing behaviors, while avoidance coping strategies are associated with more behavior problems. ${ }^{66-68)}$ Recent studies have shown that individuals with the $s / s$ genotype have fewer effective coping strategies when presented with stressful events compared to those long allele carriers, and this pattern is conspicuous in the context of a poor relationship with caregivers. ${ }^{29)}$ In our study, MNA can be interpreted as a stressful environment or cold relationship. Therefore, children with high MNA have difficulty developing active coping strategies, such as support seeking, and have fewer opportunities to learn emotional regulation from the parenting modeling. The interaction between maternal negativity and a child's behavior problems was prominent among $s / s$ allele carriers (Fig. 1). Usually, the $s$ allele is regarded as the "susceptible allele" in previous studies. That is, for $s / s$ allele carriers, high MNA is associated with more internalizing and externalizing behaviors than either $s / l$ or $l / l$ genotype. However, fewer behavioral problems were associated with the $s / s$ genotype than either $s / l$ or $l / l$ genotype when MNA was low. These results are consistent with previous studies, wherein youths homozygous for the $s$ allele had more internalizing behavior problems, particularly in the context of hostile and cold relationships with their caregivers. ${ }^{29)}$ In the present study, while there was no significant difference in externalizing and internalizing behaviors according to 5HTTPR genotypes, we found that MNA had a significant effect on the interaction between genotype and behavioral problems. Interestingly, the higher the MNA, the higher the externalizing and internalizing behaviors in the $s / s$ group. Although the clinical manifestations of externalizing and internalizing behaviors seem to be different, there is significant and substantial co-morbidity between two behavior domains. For preschoolers, in partic- ular, whose developmental stage is still immature, psychopathology is less differentiated, and children may present both behavior problems. ${ }^{69)}$ In addition, the lack of prefrontal control over limbic system activity, manifested as emotion dysregulation, is also presented as both internalizing and externalizing behavior problems. ${ }^{70}$ Morgan et al. ${ }^{71)}$ reported that early intervention in children with one or two copies of the $s$ allele was effective in improving maternal-infant attachment, whereas intervention in children with two copies of the $l$ allele had no benefit from an early intervention. Drury et al. ${ }^{72)}$ also showed that children with the $s / s$ genotype raised in an adverse environment had disturbed attachment behaviors at 54 months, including indiscrimination. However, they showed the fewest signs of indiscriminate behavior when they were placed in high quality of foster care. Surprisingly, children with the $l / l$ genotype showed no effect with intervention on the level of indiscriminate behaviors. Although, this suggests that the relationship between $s / s$ genotype and SLC6A4 polymorphism can be mediated.

When compared to children with no genetic risk, children who have genetic risk for psychopathology may benefit from positive parenting during early childhood to reduce parental negative affectivity. ${ }^{73)}$ In our study, we found MNA influenced behavior problems of the child through interaction with the $s / s 5$-HTTLPR polymorphism. Individual with the $s / s$ genotype had an enhanced outcome with low negative maternal affectivity, yet elevated vulnerability with high maternal negativity. Researchers are studying how environmental factors interact with genetic factors to affect childhood development, and genetic factors are usually separately considered. However, in this study, we found that the moderating effects of MNA on behavior problems of the child differ depending on 5-HTTLPR polymorphism. Negative environments (high MNA) may trigger the phenotypic expression of the $s / s$ genotype, while a positive environment (low MNA) allows plasticity. ${ }^{74,75)}$ Therefore, during the preschool period, which is a critical time in emotional development, early intervention for individuals who are homozygous for the $s$ allele is important for later school adjustment and overall emotional competence.

There are several limitations in this study. First, our sample size was small, which limits statistical power. Moderating effects of MNA on predicting both internaliz- 
ing and externalizing behavior problem were lower than 0.2 . Therefore, we need to be cautious when interpreting the results and more research is needed to reproduce our findings using a larger sample size. Second, genetic variation was measured within a single gene, SLC6A4, and there is the possibility that many other genetic influences remained unmeasured. Also, the distribution of the 5-HTTLPR genotype varies widely by race and ethnicity. ${ }^{17,18,42,50)}$ In this study, the majority of participants carried the $s$ variant of $S L C 6 A 4(s / s=62.2 \%, s / l=30.8 \%)$, and this limits generalization to other races, which may have fewer $s$ alleles in the population. However, the association between the 5-HTTLPR genotype and behavior problems or the occurrence of psychopathology was reported to be similar in the East Asian populations with a higher $s / s$ and lower $l / l$ genotype, compared to Western populations. ${ }^{76)}$ Genotype frequencies in this study were consistent with previous reports on SLC6A4 in Koreans ${ }^{77)}$ and other East Asians. ${ }^{78,79)}$ Third, using a subjective questionnaire to measure children's behavior patterns and maternal affectivity may be a limitation of our study. High MNA may not fully represent the real emotional influence towards children. Therefore, in further studies, it would be better to observe the children's behavior, the mother's emotion, and the interaction between them using objective methods. Fourth, there are other factors that might affect the behavior problem of children. In future studies, researchers need to evaluate how other environmental factors, such as caregivers other than mothers, family conflicts or economic status influence the interaction between genotype and behavior problems in children. In addition, we did not conduct a structured interview, such as the Kiddie Schedule for Affective Disorders and Schizophrenia (K-SADS) to identify children with other comorbid disorders, such as the attention deficit hyperactivity disorder. Thereby, there is a small possibility that undiagnosed children with psychopathology may be included. Lastly most of the children participating in this study did not have clinically significant externalizing and internalizing scores (T score, <65). Therefore, our results may not apply to a psychiatric population in clinical practice.

In conclusion, MNA was found to moderate the relationship between preschooler's internalizing and externalizing behaviors and SLC6A4 polymorphism. Children with the $s / s$ genotype may benefit from pre- ventive or treatment intervention that modulates MNA. Our findings highlighted the role of maternal affectivity in children who are genetically at high risk for developing behavior problems.

\section{- Acknowledgments}

This work was supported by research grants funded by the Samsung Welfare Foundation. We thank the participants who volunteered their time for this study.

\section{REFERENCES}

1. Bauermeister JJ, So CY, Jensen PS, Krispin O, El Din AS; Integrated Services Program Task Force. Development of adaptable and flexible treatment manuals for externalizing and internalizing disorders in children and adolescents. Rev Bras Psiquiatr 2006;28:67-71.

2. Grillo E, da Silva RJ. Early manifestations of behavioral disorders in children and adolescents. J Pediatr (Rio J) 2004;80(2 Suppl):S21-S27.

3. Achenbach TM, Edelbrock CS. The child behavior profile: II. boys aged 12-16 and girls aged 6-11 and 12-16. J Consult Clin Psychol 1979;47:223-233.

4. Angold A, Costello EJ, Erkanli A. Comorbidity. JChild Psychol Psychiatry 1999;40:57-87.

5. Russo MF, Beidel DC. Comorbidity of childhood anxiety and externalizing disorders: prevalence, associated characteristics, and validation issues. Clin Psychol Rev 1994;14:199221.

6. Liu J. Childhood externalizing behavior: theory and implications. J Child Adolesc Psychiatr Nurs 2004;17:93-103.

7. Liu J, Chen X, Lewis G. Childhood internalizing behaviour: analysis and implications. J Psychiatr Ment Health Nurs 2011;18:884-894.

8. Trucco EM, Hicks BM, Villafuerte S, Nigg JT, Burmeister M, Zucker RA. Temperament and externalizing behavior as mediators of genetic risk on adolescent substance use. J Abnorm Psychol 2016;125:565-575.

9. Min MO, Minnes S, Lang A, Weishampel P, Short EJ, Yoon S, et al. Externalizing behavior and substance use related problems at 15 years in prenatally cocaine exposed adolescents. I Adolesc 2014;37:269-279.

10. Tandon M, Cardeli E, Luby J. Internalizing disorders in early childhood: a review of depressive and anxiety disorders. Child Adolesc Psychiatr Clin N Am 2009;18:593-610.

11. Marmorstein NR. Relationships between anxiety and externalizing disorders in youth: the influences of age and gender. J Anxiety Disord 2007;21:420-432.

12. Carragher N, Krueger RF, Eaton NR, Slade T. Disorders without borders: current and future directions in the meta-structure of mental disorders. Soc Psychiatry Psychiatr Epidemiol 2015:50:339-350.

13. Achenbach TM, Edelbrock CS. The classification of child psy- 
chopathology: a review and analysis of empirical efforts. Psychol Bull 1978;85:1275-1301.

14. DiLalla LF, Elam KK, Smolen A. Genetic and gene-environment interaction effects on preschoolers' social behaviors. Dev Psychobiol 2009; 51:451-464.

15. Cosgrove VE, Rhee SH, Gelhorn HL, Boeldt D, Corley RC, Ehringer MA, et al. Structure and etiology of co-occurring internalizing and externalizing disorders in adolescents. J Abnorm Child Psychol 2011;39:109-123.

16. Schmidt LA, Fox NA, Hamer DH. Evidence for a gene-gene interaction in predicting children's behavior problems: association of serotonin transporter short and dopamine receptor D4 long genotypes with internalizing and externalizing behaviors in typically developing 7-year-olds. Dev Psychopathol 2007:19:1105-1116.

17. Gelernter J, Kranzler H, Cubells JF. Serotonin transporter protein (SLC6A4) allele and haplotype frequencies and linkage disequilibria in African- and European-American and Japanese populations and in alcohol-dependent subjects. Hum Genet 1997; 101:243-246.

18. Goldman N, Glei DA, Lin YH, Weinstein M. The serotonin transporter polymorphism (5-HTTLPR): allelic variation and links with depressive symptoms. Depress Anxiety 2010;27: 260-269.

19. Heils A, Teufel A, Petri S, Stöber G, Riederer P, Bengel D, et al. Allelic variation of human serotonin transporter gene expression. J Neurochem 1996;66:2621-2624.

20. Greenberg BD, Tolliver TJ, Huang SJ, Li Q, Bengel D, Murphy DL. Genetic variation in the serotonin transporter promoter region affects serotonin uptake in human blood platelets. Am J Med Genet 1999;88:83-87.

21. Collier DA, Stöber G, Li T, Heils A, Catalano M, Di Bella D, et al. A novel functional polymorphism within the promoter of the serotonin transporter gene: possible role in susceptibility to affective disorders. Mol Psychiatry 1996;1:453-460.

22. Caspi A, Sugden K, Moffitt TE, Taylor A, Craig IW, Harrington $\mathrm{H}$, et al. Influence of life stress on depression: moderation by a polymorphism in the 5-HTT gene. Science 2003;301: 386-389.

23. Kaufman J, Yang BZ, Douglas-Palumberi H, Houshyar S, Lipschitz D, Krystal JH, et al. Social supports and serotonin transporter gene moderate depression in maltreated children. Proc Natl Acad Sci U S A 2004;101:17316-17321.

24. Feinn R, Nellissery M, Kranzler HR. Meta-analysis of the association of a functional serotonin transporter promoter polymorphism with alcohol dependence. Am J Med Genet B Neuropsychiatr Genet 2005;133B:79-84.

25. Eisenberg N, Sulik MJ. Emotion-related self-regulation in children. Teach Psychol 2012;39:77-83.

26. Eisenberg N, Spinrad TL, Eggum ND. Emotion-related self-regulation and its relation to children's maladjustment. Annu Rev Clin Psychol 2010;6:495-525.

27. Supplee LH, Skuban EM, Shaw DS, Prout J. Emotion regulation strategies and later externalizing behavior among European American and African American children. Dev Psychopathol 2009;21:393-415.

28. Doan SN, Fuller-Rowell TE, Evans GW. Cumulative risk and adolescent's internalizing and externalizing problems: the mediating roles of maternal responsiveness and self-regulation. Dev Psychol 2012;48:1529-1539.

29. Cline JI, Belsky J, Li Z, Melhuish E, Lysenko L, McFarquhar T, et al. Take your mind off it: coping style, serotonin transporter linked polymorphic region genotype (5-HTTLPR), and children's internalizing and externalizing problems. Dev Psychopathol 2015;27:1129-1143.

30. Kopp CB. Regulation of distress and negative emotions: a developmental view. Dev Psychol 1989;25:343-354.

31. Campbell SB, Denham SA, Howarth GZ, Jones SM, Whittaker JV, Williford AP, et al. Commentary on the review of measures of early childhood social and emotional development: conceptualization, critique, and recommendations. J App/ Dev Psychol 2016;45:19-41.

32. Batum P, Yagmurlu B. What counts in externalizing behaviors? The contributions of emotion and behavior regulation. Curr Psychol 2007;25:272-294.

33. Eisenberg N, Morris AS. Children's emotion-related regulation. Adv Child Dev Behav 2002;30:189-229.

34. Eisenberg N, Fabes RA. Mothers' reactions to children's negative emotions: relations to children's temperament and anger behavior. Merrill-Palmer Q 1994;40:138-156.

35. Slatcher RB, Trentacosta CJ. Influences of parent and child negative emotionality on young children's everyday behaviors. Emotion 2012;12:932-942.

36. Watson D, Clark LA. Negative affectivity: the disposition to experience aversive emotional states. Psychol Bull 1984;96: 465-490.

37. Eisenberg N, Zhou Q, Spinrad TL, Valiente C, Fabes RA, Liew J. Relations among positive parenting, children's effortful control, and externalizing problems: a three-wave longitudinal study. Child Dev 2005;76:1055-1071.

38. Denham SA, Mitchell-Copeland J, Strandberg K, Auerbach S, Blair K. Parental contributions to preschoolers' emotional competence: direct and indirect effects. Motiv Emot 1997;21: 65-86.

39. Sulik MJ, Eisenberg N, Lemery-Chalfant K, Spinrad TL, Silva $\mathrm{KM}$, Eggum ND, et al. Interactions between serotonin transporter gene haplotypes and quality of mothers' parenting predict the development of children's noncompliance. Dev Psychol 2012;48:740-754.

40. van ljzendoorn $\mathrm{MH}$, Belsky J, Bakermans-Kranenburg MJ. Serotonin transporter genotype 5HTTLPR as a marker of differential susceptibility? A meta-analysis of child and adolescent gene-by-environment studies. Transl Psychiatry 2012;2: e147.

41. Park $\mathrm{H}$, Seo $\mathrm{Y}$, Lee J. A study of concurrent validities of K-WPPSI-IV. Korean J Child Stud 2015;36:65-83. 
42. Nakamura M, Ueno S, Sano A, Tanabe H. The human serotonin transporter gene linked polymorphism (5-HTTLPR) shows ten novel allelic variants. Mol Psychiatry 2000;5:32-38.

43. Oh KJ, Kim YA. Child behavior checklist for ages 1.5-5. Korean version. Seoul:Huno;2008.

44. Buss AH, Plomin R. Temperament: early developing personality traits. Hillsdale, NJ;London:Lawrence Erlbaum;1984.

45. Bolin JH. Hayes, Andrew F. (2013). Introduction to mediation, moderation, and conditional process analysis: a regressionbased approach. New York, NY: The Guilford Press. J Educ Meas 2014; 51:335-337.

46. Hayes AF. Beyond Baron and Kenny: statistical mediation analysis in the new millennium. Commun Monogr 2009;76. 408-420.

47. Kim WK, Kim HS, Kim WJ, Lee KY, Park H, Kim CH, et al. Serotonin transporter gene polymorphism and migraine in the Korean population. Headache 2005;45:1056-1060.

48. Pae CU, Kim JJ, Lee SJ, Lee CU, Lee C, Paik IH, et al. Polymorphism of the serotonin transporter gene and symptomatic dimensions of schizophrenia in the Korean population. Neuropsychobiology 2003;47:182-186.

49. Kim SJ, Badner J, Cheon KA, Kim BN, Yoo HJ, Kim SJ, et al. Family-based association study of the serotonin transporter gene polymorphisms in Korean ADHD trios. Am JMed Genet B Neuropsychiatr Genet 2005;139B:14-18.

50. Kunugi $\mathrm{H}$, Hattori $M$, Kato T, Tatsumi M, Sakai T, Sasaki T, et al. Serotonin transporter gene polymorphisms: ethnic difference and possible association with bipolar affective disorder. Mol Psychiatry 1997;2:457-462.

51. Cervilla JA, Rivera M, Molina E, Torres-González F, Bellón JA, Moreno B, et al. The 5-HTTLPR s/s genotype at the serotonin transporter gene (SLC6A4) increases the risk for depression in a large cohort of primary care attendees: the PREDICT-gene study. Am J Med Genet B Neuropsychiatr Genet 2006;141B: 912-917.

52. Oberlander TF, Papsdorf M, Brain UM, Misri S, Ross C, Grunau RE. Prenatal effects of selective serotonin reuptake inhibitor antidepressants, serotonin transporter promoter genotype (SLC6A4), and maternal mood on child behavior at 3 years of age. Arch Pediatr Adolesc Med 2010;164:444-451.

53. Newland RP, Crnic KA. Mother-child affect and emotion socialization processes across the late preschool period: predictions of emerging behavior problems. Infant Child Dev 2011;20:371-388.

54. Buckner JC, Mezzacappa E, Beardslee WR. Characteristics of resilient youths living in poverty: the role of self-regulatory processes. Dev Psychopathol 2003;15:139-162.

55. Silk JS, Shaw DS, Forbes EE, Lane TL, Kovacs M. Maternal depression and child internalizing: the moderating role of child emotion regulation. J Clin Child Adolesc Psychol 2006;35: 116-126.

56. Tan PZ, Lee KH, Dahl RE, Nelson EE, Stroud LJ, Siegle GJ, et al. Associations between maternal negative affect and ado- lescent's neural response to peer evaluation. Dev Cogn Neurosci 2014;8:28-39.

57. Eisenberg N, Guthrie IK, Fabes RA, Shepard S, Losoya S, Murphy BC, et al. Prediction of elementary school children's externalizing problem behaviors from attentional and behavioral regulation and negative emotionality. Child Dev 2000; 71:1367-1382.

58. Paulussen-Hoogeboom MC, Stams GJ, Hermanns JM, Peetsma TT. Child negative emotionality and parenting from infancy to preschool: a meta-analytic review. Dev Psychol 2007;43:438-453.

59. Lucki I. The spectrum of behaviors influenced by serotonin. Biol Psychiatry 1998;44:151-162.

60. Alexander N, Kuepper Y, Schmitz A, Osinsky R, Kozyra E, Hennig J. Gene-environment interactions predict cortisol responses after acute stress: implications for the etiology of depression. Psychoneuroendocrinology 2009;34:1294-1303.

61. Alexander N, Klucken T, Koppe G, Osinsky R, Walter B, Vaitl $\mathrm{D}$, et al. Interaction of the serotonin transporter-linked polymorphic region and environmental adversity: increased amygdala-hypothalamus connectivity as a potential mechanism linking neural and endocrine hyperreactivity. Biol Psychiatry 2012;72:49-56.

62. Williams LM, Gatt JM, Schofield PR, Olivieri G, Peduto A, Gordon E. 'Negativity bias' in risk for depression and anxiety: brain-body fear circuitry correlates, 5-HTT-LPR and early life stress. Neuroimage 2009;47:804-814.

63. Canli T, Omura K, Haas BW, Fallgatter A, Constable RT, Lesch KP. Beyond affect: a role for genetic variation of the serotonin transporter in neural activation during a cognitive attention task. Proc Natl Acad Sci U S A 2005;102:12224-12229.

64. Iacoboni M. Neural mechanisms of imitation. Curr Opin Neurobiol 2005; 15:632-637.

65. You JS, Hu SY, Chen B, Zhang HG. Serotonin transporter and tryptophan hydroxylase gene polymorphisms in Chinese patients with generalized anxiety disorder. Psychiatr Genet 2005; 15:7-11.

66. Connor-Smith JK, Compas BE, Wadsworth ME, Thomsen AH, Saltzman $\mathrm{H}$. Responses to stress in adolescence: measurement of coping and involuntary stress responses. I Consult Clin Psychol 2000;68:976-992.

67. Brittian AS, Toomey RB, Gonzales NA, Dumka LE. Perceived discrimination, coping strategies, and Mexican origin adolescents' internalizing and externalizing behaviors: examining the moderating role of gender and cultural orientation. Appl Dev Sci 2013;17:4-19.

68. Tandon SD, Dariotis JK, Tucker MG, Sonenstein FL. Coping, stress, and social support associations with internalizing and externalizing behavior among urban adolescents and young adults: revelations from a cluster analysis. J Adolesc Health 2013;52:627-633.

69. Willner CJ, Gatzke-Kopp LM, Bray BC. The dynamics of internalizing and externalizing comorbidity across the early 
school years. Dev Psychopathol 2016;28:1033-1052.

70. Beauchaine TP. Future directions in emotion dysregulation and youth psychopathology. I Clin Child Adolesc Psychol 2015:44:875-896.

71. Morgan B, Kumsta R, Fearon P, Moser D, Skeen S, Cooper P, et al. Serotonin transporter gene (SLC6A4) polymorphism and susceptibility to a home-visiting maternal-infant attachment intervention delivered by community health workers in South Africa: reanalysis of a randomized controlled trial. PLoS Med 2017; 14:e1002237.

72. Drury SS, Gleason MM, Theall KP, Smyke AT, Nelson CA, Fox NA, et al. Genetic sensitivity to the caregiving context: the influence of 5httlpr and BDNF val66met on indiscriminate social behavior. Physiol Behav 2012;106:728-735.

73. Leve LD, Harold GT, Ge X, Neiderhiser JM, Shaw D, Scaramella LV, et al. Structured parenting of toddlers at high versus low genetic risk: two pathways to child problems. J Am Acad Child Adolesc Psychiatry 2009;48:1102-1109.

74. Windhorst DA, Mileva-Seitz VR, Rippe RC, Tiemeier H, Jaddoe VW, Verhulst FC, et al. Beyond main effects of genesets: harsh parenting moderates the association between a dopamine gene-set and child externalizing behavior. Brain Behav 2016;6:e00498.

75. Shanahan MJ, Hofer SM. Social context in gene-environment interactions: retrospect and prospect. J Gerontol B Psychol SCi Soc Sci 2005; 60:65-76.

76. Taylor SE, Way BM, Welch WT, Hilmert CJ, Lehman BJ, Eisenberger NI. Early family environment, current adversity, the serotonin transporter promoter polymorphism, and depressive symptomatology. Biol psychiatry 2006;60:671-676.

77. Kim DK, Lim SW, Lee S, Sohn SE, Kim S, Hahn CG, et al. Serotonin transporter gene polymorphism and antidepressant response. Neuroreport 2000;11:215-219.

78. Tsai SJ, Hong CJ, Yu YW, Lin CH, Song HL, Lai HC, et al. Association study of a functional serotonin transporter gene polymorphism with schizophrenia, psychopathology and clozapine response. Schizophr Res 2000;44:177-181.

79. Kumakiri C, Kodama K, Shimizu E, Yamanouchi N, Okada S, Noda S, et al. Study of the association between the serotonin transporter gene regulatory region polymorphism and personality traits in a Japanese population. Neuroscience lett 1999; 263:205-207. 